\title{
TCN, an AKT inhibitor, exhibits potent antitumor activity and enhances radiosensitivity in hypoxic esophageal squamous cell carcinoma in vitro and in vivo
}

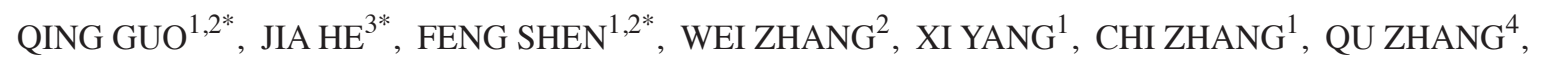 \\ JUN-XING HUANG ${ }^{2}$, ZHENG-DONG WU ${ }^{2}$, XIN-CHEN SUN ${ }^{1}$ and SHENG-BIN DAI ${ }^{2}$ \\ ${ }^{1}$ Department of Radiotherapy, The First Affiliated Hospital of Nanjing Medical University, Nanjing, Jiangsu 210029; \\ ${ }^{2}$ Department of Oncology, People's Hospital of Taizhou, Taizhou, Jiangsu 225300; ${ }^{3}$ Department of Radiotherapy, \\ People's Hospital of Jiangyin, Wuxi, Jiangsu 214400; ${ }^{4}$ Department of Radiotherapy, \\ Hubei Cancer Hospital, Wuhan, Hubei 430079, P.R. China
}

Received April 22, 2015; Accepted September 22, 2016

DOI: $10.3892 / \mathrm{ol} .2016 .5515$

\begin{abstract}
The aim of the present study was to investigate the radiosensitization effect of triciribine (TCN) on human esophageal squamous cell carcinoma (ESCC) in normoxia or hypoxia and its mechanism. The cytotoxicity and radiosensitization mechanism of TCN were investigated by Cell Counting Kit 8, clonogenic assay, flow cytometry, western blotting (WB) and immunofluorescence staining of phosphohistone H2A.X, Ser139 ( $\gamma$-H2AX) in ESCC in vitro, while the protein expression levels of AKT, phosphorylated (p)-AKT, hypoxia-inducible factor (HIF)- $1 \alpha$ and vascular endothelial growth factor (VEGF) were evaluated by WB in vivo. The cytotoxicity of TCN was dose dependent. Upon exposure to TCN, ESCC cells in hypoxia treated with 4-Gy radiotherapy exhibited an evidently higher apoptotic rate than cells subjected to other treatments. TCN could significantly inhibit the protein expression of p-AKT, HIF-1 $\alpha$ and VEGF in vitro and in vivo. The present results suggested that TCN can effectively inhibit AKT, p-AKT, HIF-1 $\alpha$ and VEGF, thus conferring radiosensitivity to ESCC in vitro and vivo. TCN is considered as an adjuvant in radiotherapy of ESCC in clinical application.
\end{abstract}

Correspondence to: Dr Xin-Chen Sun, Department of Radiotherapy, The First Affiliated Hospital of Nanjing Medical University, 300 Guangzhou Road, Nanjing, Jiangsu 210029, P.R. China

E-mail: sunxinchen2012@163.com

Professor Sheng-Bin Dai, Department of Oncology, People's Hospital of Taizhou, 395 South Hailing Road, Taizhou, Jiangsu 225300, P.R. China

E-mail: tzdsb@hotmail.com

*Contributed equally

Key words: TCN, AKT, ESCC, radiotherapy

\section{Introduction}

Esophageal cancer (EC) is the sixth leading cause of cancer mortality, with 17,990 new cases and 15,210 mortalities reported in 2013 (1). The major histological type in China is squamous cell carcinoma (SCC), which accounts for $>90 \%$ of all types of EC $(2,3)$. Locally advanced esophageal carcinoma is known to be refractory to a single modality of treatment (4). Patients with unresectable or medically inoperable disease are usually treated with radiation therapy and concurrent chemotherapy $(4,5)$. However, hypoxic environments contribute to malignant behavior, including tumor progression, invasion and radiation resistance (6), which are major barriers to the success of radiation therapy. Therefore, improving the hypoxic environment to enhance the radiation sensitivity of cancer cells has become an urgent task.

Recently, a number of studies have focused on the oncogenic phosphatidylinositol-3-kinase (PI3K)/AKT pathway, also known as the protein kinase B pathway (7). The PI3K/AKT pathway phosphorylates and activates AKT to phosphorylated (p)-AKT, which plays a critical role in promoting a malignant phenotype and has prognostic significance in a number of solid tumors $(7,8)$. Previous reports also suggested that $\mathrm{p}$-AKT overexpression may correlate with a poor prognosis $(9,10)$. Hypoxic environments can activate a specific set of tumor-promoting factors, including signal transducer and activator of AKT and hypoxia-inducible factor (HIF)-1 (11,12). HIF-1 can activate the vascular endothelial growth factor (VEGF) gene in response to PI3K/AKT and mammalian target of rapamycin (mTOR) signaling to regulate the adaptation to hypoxic conditions (13). In addition, p-AKT enhances the expression of the HIF-1 $\alpha$ gene and its target genes such as VEGF $(14,15)$. HIF-1 $\alpha$ is an oxygen-sensitive subunit, and regulates $>100$ genes involved in cell survival, tumor metabolism, proliferation, invasion and angiogenesis to resist various treatments (14-17).

Triciribine (TCN), as an effective AKT inhibitor, has been demonstrated to effectively inhibit p-AKT (18). It has been reported that TCN potently and selectively inhibits the activation, 
dimerization and nuclear translocation of AKT, resulting in an increase in the apoptosis of prostate carcinoma cells (19).

Thus, we hypothesize that TCN inhibits AKT and HIF-1 $\alpha$ expression, and improves tumor microenvironment in esophageal SCC (ESCC) cells. In other words, TCN can radiosensitize human ESCC cells by decreasing AKT and HIF-1 $\alpha$ expression in hypoxia. To confirm the hypothesis described above, the present study examined the effects of TCN and/or X-rays on human ESCC cells in hypoxia both in vitro and in vivo.

\section{Materials and methods}

Reagents. The AKT inhibitor TCN ( $>99 \%$ ) was purchased from Selleck Chemicals (Houston, TX, USA), while RPMI-1640 medium and fetal bovine serum (FBS) were obtained from Gibco (Thermo Fisher Scientific, Inc., Waltham, MA, USA). Cell Counting Kit (CCK) 8, streptomycin, penicillin and dimethyl sulfoxide were obtained from Beyotime Institute of Biotechnology (Haimen, China). Antibodies against AKT (9272S) and p-AKT (4060S) were purchased from Cell Signaling Technology, lnc. (Danvers, MA, USA), while antibodies against HIF-1 $\alpha$ (sc-13515), VEGF (sc-117031) and $\beta$-actin (sc-47778) were obtained from Santa Cruz Biotechnology Inc. (Dallas, TX, USA). Mouse anti-phospho-histone H2AX, Ser139 ( $\gamma$-H2.AX) antibody (MAB504A) was obtained from EMD Millipore (Billerica, MA, USA).

Cell culture. The ESCC cell line ECA109 (supplied by Shanghai Institute of Cell Biology, Shanghai, China) was cultured in RPMI-1640 medium supplemented with $10 \%$ Gibco FBS (Thermo Fisher Scientific, Inc.), 100 U/ml penicillin and $100 \mathrm{mg} / \mathrm{ml}$ streptomycin. ECA109 cells were maintained at $37^{\circ} \mathrm{C}$ in a humidified incubator at $5 \% \mathrm{CO}_{2}$, $20 \% \mathrm{O}_{2}$ or $1 \% \mathrm{O}_{2}$. Hypoxic conditions were created in an hypoxia chamber, where the cells were incubated in a modular chamber flushed with a complex air of $1 \% \mathrm{O}_{2}, 5 \%$ $\mathrm{CO}_{2}$ and $94 \% \mathrm{~N}_{2}$ at $37^{\circ} \mathrm{C}$.

Treatment with irradiation. ECA109 cells were irradiated with $6 \mathrm{MV}$ X-rays (Elekta Instrument AB, Stockholm, Sweden) at a dose rate of $5.66 \mathrm{~Gy} / \mathrm{min}(2,4,6$ and $8 \mathrm{~Gy})$ at room temperature. The tumors of nude mice were irradiated with $4 \mathrm{MV}$ X-rays (6 Gy) using an RS-2000 biological irradiator (Shanghai Bio-Chain Institute of Cell Biology, Shanghai, China) at a dose rate of $4.48 \mathrm{~Gy} / \mathrm{min}$ at room temperature.

CCK8 assay. Cell viability was determined using CCK8 assay (Beyotime Institute of Biotechnology, Haimen, China). ECA109 cells (4,000 cells/well) were cultured in 96-well plates for $24 \mathrm{~h}$ following TCN treatment with different concentrations $(0,0.5,2,4$ and $8 \mu \mathrm{mol} / \mathrm{l})$. Cell density was measured by CCK8 assay following the manufacturer's protocol. Briefly, $10 \mu 1$ of CCK8 (at $5 \mathrm{mg} / \mathrm{ml}$ ) was added to each well at a final concentration of $0.5 \mathrm{mg} / \mathrm{ml}$, and the cells were incubated for $4 \mathrm{~h}$ at $37^{\circ} \mathrm{C}$. Then, the samples absorbance at $490 \mathrm{~nm}$ was read with a microplate reader (model 630; Bio-Rad Laboratories, Inc., Hercules, CA, USA).

Clonogenic survival assay. ECA109 cells were plated in 6-well plates at a specific density on the basis of the dose of
X-rays received. Then, cells treated with or without TCN with different doses of X-rays were assessed by clonogenic assay. Briefly, the cells were treated with or without TCN for $24 \mathrm{~h}$, and then irradiated with $0,2,4,6$ and 8 Gy at room temperature. The cells were grown at $37^{\circ} \mathrm{C}$ for 12 days, fixed with methanol, stained with Giemsa, and then scored by counting with an inverted microscope, using the standard definition of a colony consisting of $\geq 50$ cells. The surviving fraction (SF) was defined as follows: $\mathrm{SF}=$ (mean number of colonies)/(number of cells inoculated $x$ plating efficiency).

Measurement of apoptosis by flow cytometry. Treated ECA109 cells were plated in 6-well plates at a specific density. The cells were exposed to X-rays (4 Gy) after TCN treatment in normoxia or hypoxia for $24 \mathrm{~h}$. After $48 \mathrm{~h}$, the cells were collected and labeled with Annexin $\mathrm{V}$ and propidium iodide according to the manufacturer's protocol. Cell death was analyzed by flow cytometry using light scatter characteristics (BD Biosciences, Franklin Lakes, NJ, USA). The apoptosis rate was determined by Annexin V-FITC Apoptosis Detection kit Nanjing KeyGen Biotech Co., Ltd. (Nanjing, China). This experiment was repeated $\geq 3$ times.

Western blot assay. Treated ECA109 cells were lysed in SDS Lysis Buffer (Sigma-Aldrich; Merck Millipore, Darmstadt, Germany) and then centrifuged at $14,000 \times \mathrm{g}\left(15 \mathrm{~min}, 4^{\circ} \mathrm{C}\right)$. Protein concentrations of the samples were calculated with a bicinchoninic acid kit (Beyotime Institute of Biotechnology). Equal amounts of protein were separated by 6 or $10 \%$ SDS-PAGE, transferred to Protran ${ }^{\circledR}$ nitrocellulose membranes (Schleicher \& Schuell BioScience GmbH, Inc., Dassel, Germany), and then blocked with TBS (pH 7.4) containing $0.05 \%$ Tween 20 and 5\% nonfat milk. The membranes were incubated overnight at $4^{\circ} \mathrm{C}$ by gentle agitation with various primary antibodies: Anti-AKT antibody (1:500), anti-p-AKT antibody (1:500), anti-HIF-1 $\alpha$ antibody (1:500), anti-VEGF antibody $(1: 250)$ and anti- $\beta$-actin antibody $(1: 250)$. The following day, the membrane was incubated with alkaline phosphatase-conjugated goat anti-mouse immunoglobulin (Ig) G or goat anti-rabbit IgG as secondary antibody $(1: 2,000$; BS13271; Bioworld Technology, Inc., St. Louis Park, MN, USA) for $1 \mathrm{~h}$ at room temperature. The blots were visualized using the SuperSignal West Femto kit (Pierce; Thermo Fisher Scientific, Inc.).

Immunofluorescence staining of $\gamma$-H2AX. ECA109 cells were grown on glass coverslips, treated with or without TCN, and then administered X-rays (1 Gy). The cells were glass-fixed with acetone and permeabilized with $0.1 \%$ Triton X-100 in PBS for $5 \mathrm{~min}$ at room temperature. Next, the cells were incubated with an anti- $\gamma-\mathrm{H} 2 \mathrm{AX}$ antibody (diluted $1: 200$ ) at $4^{\circ} \mathrm{C}$ overnight and then incubated with fluorescein isothiocyanate-conjugated secondary antibody (diluted 1:100; ab2492; Abcam, Shanghai, China) for $1 \mathrm{~h}$ at room temperature. After washing in PBS, cells were incubated in the dark with DAPI (at a dilution of 1:35 in $4 \%$ paraformaldehyde) for $5 \mathrm{~min}$. Then, the slides were examined with at $\mathrm{x} 400$ magnification with a confocal laser scanning microscope (LSM 510; Zeiss GmbH, Jena, Germany). For each treatment condition, the number of 
A

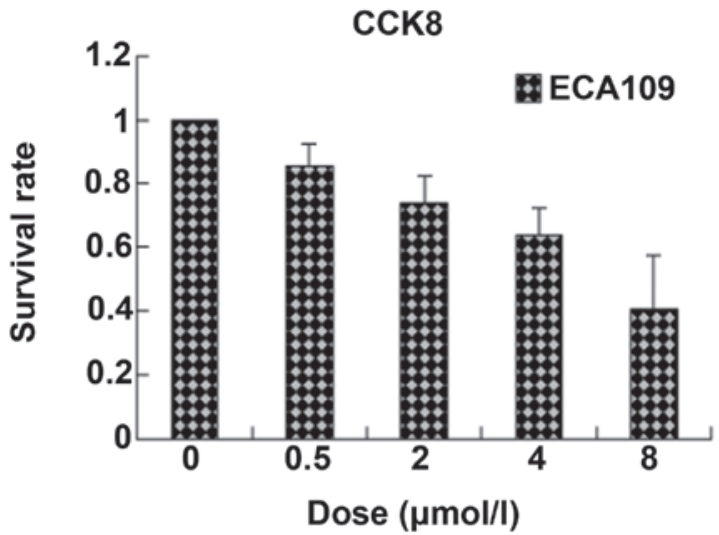

B

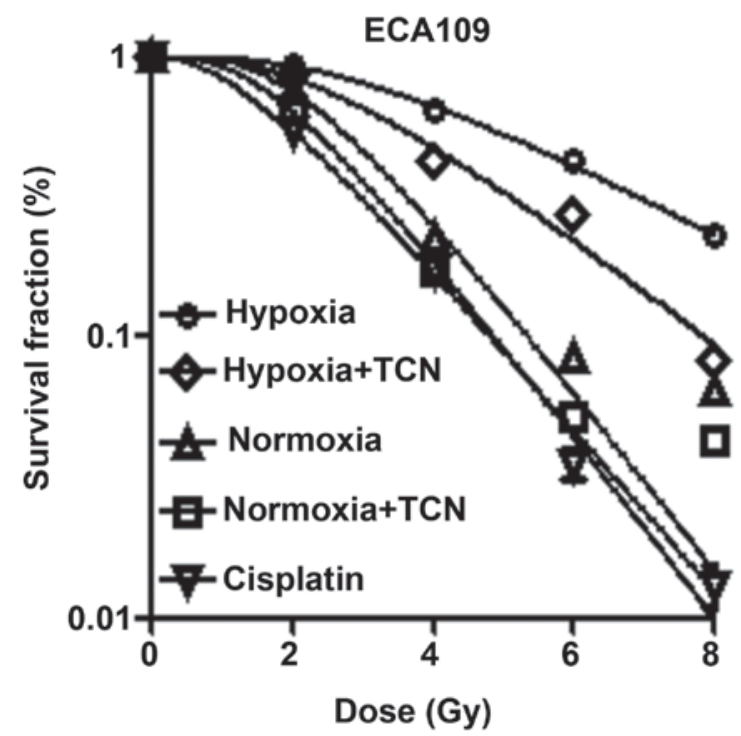

Figure 1. (A) TCN inhibited the proliferation of ESCC cells in a dose-dependent manner, with a half maximal inhibitory concentration of $6.155 \mu \mathrm{mol} / 1$. (B) Clonogenic survival assay of ECA109 cells. Cells were exposed to 0-8 Gy with or without TCN $(4 \mu \mathrm{mol} / 1)$ in normoxia or hypoxia. ESCC, esophageal squamous cell carcinoma; TCN, triciribine.

$\gamma$-H2AX foci were counted in $\geq 100$ cells from randomly captured images.

In vivo experiment. A total of 24 four-week-old male BALB/c nude mice (weight, 18-20 g) were acquired from Nanjing Medical University Animal Center (Nanjing, China). The animals, which were allowed free feeding and drinking, were housed under conventional conditions with constant temperature and humidity, and were maintained on a 12:12-h dark-light cycle. The mice were injected subcutaneously with ECA109 cells $\left(5 \times 10^{6}\right.$ cells in $\left.0.1 \mathrm{ml} \mathrm{PBS}\right)$ at one site of the right armpit separately. When the tumor mass became obvious $\left(\sim 150 \mathrm{~mm}^{3}\right)$, the mice were randomly divided into four subgroups: Control group, $25 \mathrm{mg} / \mathrm{kg}$ TCN group, ionizing radiation (IR) (4 Gy) group and $25 \mathrm{mg} / \mathrm{kg}$ TCN plus IR group. Each group contained 6 mice. For the control group, PBS alone was injected every 2 days, and TCN was administered to the mice 3 times/week for 4 weeks. On the fifth day, the mice were administered a single dose of $4 \mathrm{~Gy}$ X-rays ( $4.48 \mathrm{~Gy} / \mathrm{min})$ with the RS-2000 biological irradiator. The mice received TCN twice more after IR. On day 25 , the mice were sacrificed. Tumor volume was calculated with the formula: Tumor volume $\left(\mathrm{mm}^{3}\right)=$ length
Table I. Radiosensitization activity of TCN in ECA109 cells.

\begin{tabular}{lcccc}
\hline ECA109 & $\mathrm{D}_{0}(\mathrm{~Gy})$ & $\mathrm{D}_{\mathrm{q}}(\mathrm{Gy})$ & $\mathrm{SF}_{2}$ & $\mathrm{SER}_{\mathrm{D} 0}$ \\
\hline Hypoxia & 5.01 & 2.56 & 0.85 & 1.00 \\
Hypo + TCN & 3.68 & 2.21 & 0.65 & 1.36 \\
Normoxia & 3.34 & 2.15 & 0.63 & 1.50 \\
Nor + TCN & 3.03 & 1.14 & 0.61 & 1.65 \\
Cisplatin & 2.65 & 0.71 & 0.47 & 1.89 \\
\hline
\end{tabular}

TCN, triciribine; Hypo, hypoxia; Nor, normoxia; $\mathrm{D}_{0}$, mean lethal dose; $\mathrm{D}_{\mathrm{q}}$, quasi-threshold dose; $\mathrm{SF}_{2}$, surviving fraction at $2 \mathrm{~Gy} ; \mathrm{SER}$, sensitization enhancement ratio.

diameter $(\mathrm{mm}) \mathrm{x}$ width diameter $(\mathrm{mm})^{2} / 2$. Mouse tumors were analyzed by WB for p-AKT, AKT, HIF-1 $\alpha$ and VEGF. All the procedures were performed in accordance with the guidelines of the laboratory animal ethics committee of Nanjing Medical University (Nanjing, China).

Statistical analysis. All experiments were performed in triplicate. Each datum represents the mean \pm standard deviation or the mean \pm standard error of mean of different experiments under the same conditions. Statistical analysis of the results was performed using GraphPad Prism program version 5.0 (GraphPad Software, Inc., La Jolla, CA, USA) and SPSS statistical software system for Windows version 16.0 (SPSS, Inc., Chicago, IL, USA). Statistical significance between each treated group and the control was analyzed using the independent $t$-test. $\mathrm{P}<0.05$ was considered to indicate a statistically significant difference.

\section{Results}

Half maximal inhibitory concentration $\left(I C_{50}\right)$ for TCN in ESCC ECA109 cells. The viability of ECA109 cells was observed at various concentrations of TCN $(0,0.5,2,4$ and $8 \mu \mathrm{mol} / \mathrm{l}$ ) for $24 \mathrm{~h}$ according to CCK8 assay (Fig. 1A). The $\mathrm{IC}_{50}$ value for the ECA109 cell line was extrapolated at $24 \mathrm{~h}$, and was calculated to be $6.155 \mu \mathrm{mol} / 1$. Thus, a low concentrations of TCN $(2 \mu \mathrm{mol} / \mathrm{l})$ was selected for subsequent experiments with the ECA109 cell line.

TCN is an effective radiosensitizer of ESCC cells in normoxia and hypoxia in vitro. ESCC ECA109 cells were treated for $24 \mathrm{~h}$ with TCN $(4 \mu \mathrm{mol} / \mathrm{l})$ to investigate the effects of $\mathrm{TCN}$ on radiotherapy sensitization of ESCC cells in normoxia and hypoxia. Clonogenic assays revealed the radiation dose-response survival curves for ESCC ECA109 cells, and suggested radioresistance of ESCC cells (Fig. 1B). Notably, the effect of TCN was more obvious in hypoxia as compared with normoxia in ECA109 cells. When a low cytotoxic concentration $(4 \mu \mathrm{mol} / \mathrm{l})$ was selected in vitro, TCN diminished clonogenic survival to a great extent and radiosensitized ECA109 similarly under conditions of hypoxia [sensitization enhancement ratio $(\mathrm{SER})=1.36]$ and normoxia (SER=1.50). By contrast, hypoxic cells in normoxia reduced their ability to form colonies after irradiation, indicating hypoxia-induced radioresistance 
A

Normoxia
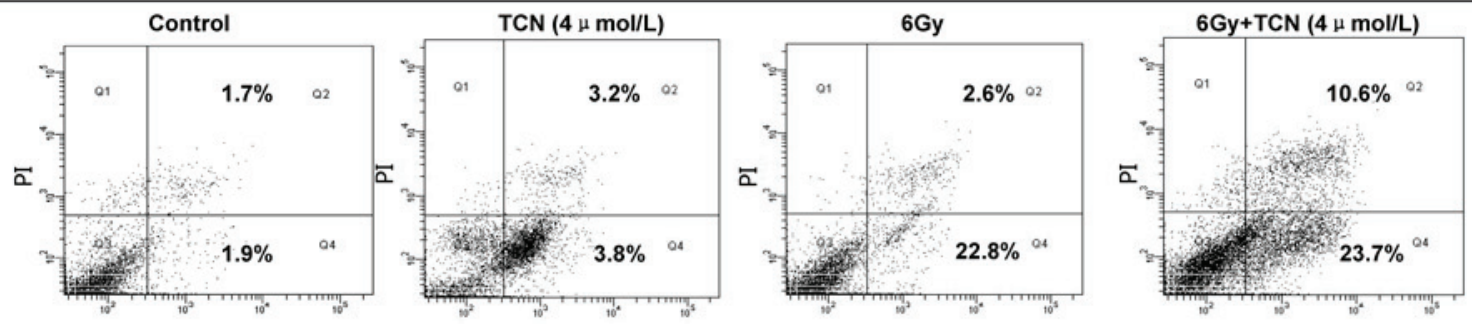

AV

Hypoxia AV

AV

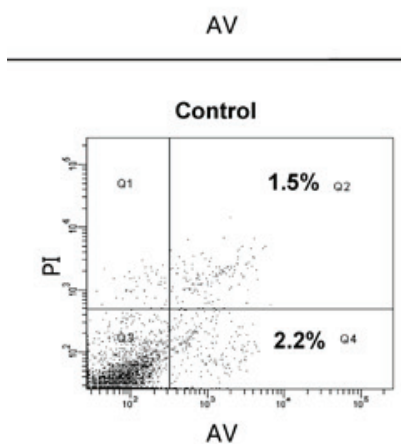

B
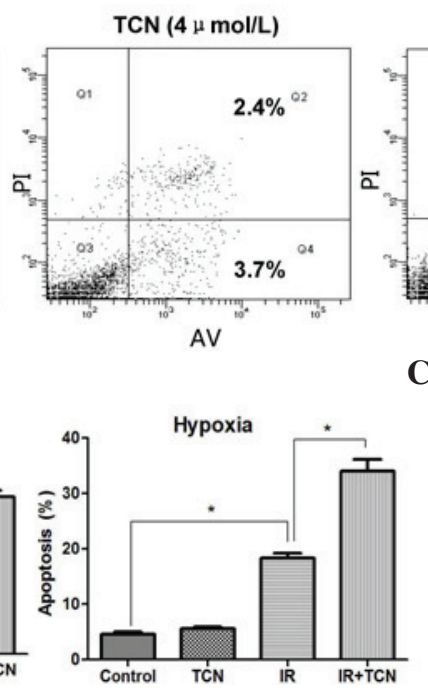

6Gy

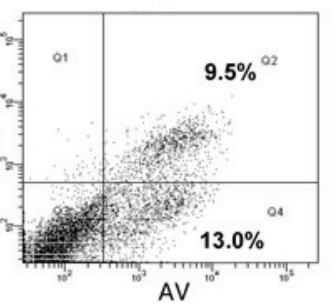

C

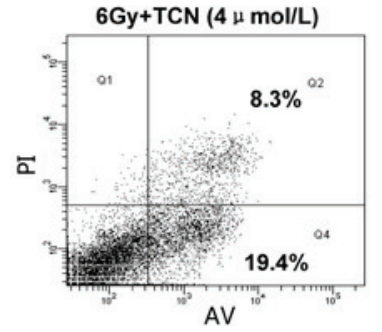

Figure 2. (A) The effect of $6 \mathrm{~Gy}+\mathrm{TCN}$ in cell apoptosis is significant. ${ }^{*}$ Normoxia, $\mathrm{P}=0.002$; hypoxia, $\mathrm{P}=0.006$. (B) TCN $(4 \mu$ mol/l) significantly enhanced the irradiation-induced apoptosis of ECA109 cells under hypoxia and normoxia (" $\mathrm{P}=0.003)$. (C) Determination of TCN-induced $\gamma$-H2AX foci in ECA109 cells at $0.5,4$ and $24 \mathrm{~h}$ after $1 \mathrm{~Gy} \pm 4 \mu \mathrm{mol} / 1 \mathrm{TCN}$ treatment (mean \pm standard error of the mean, $\mathrm{n}=3$ ). ${ }^{*} \mathrm{P}=0.0003 \mathrm{and} \mathrm{P}=0.0008$ at 4 and $24 \mathrm{~h}$, respectively. TCN, triciribine; IR, ionizing radiation; $\gamma$-H2AX, phospho-histone H2A.X, Ser139; nb, number.

\section{A}

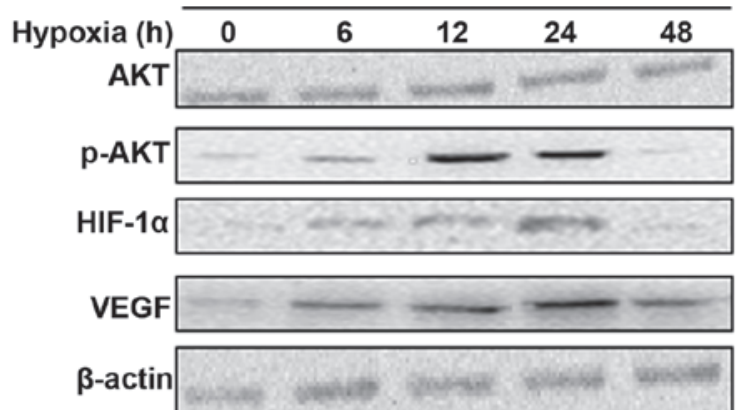

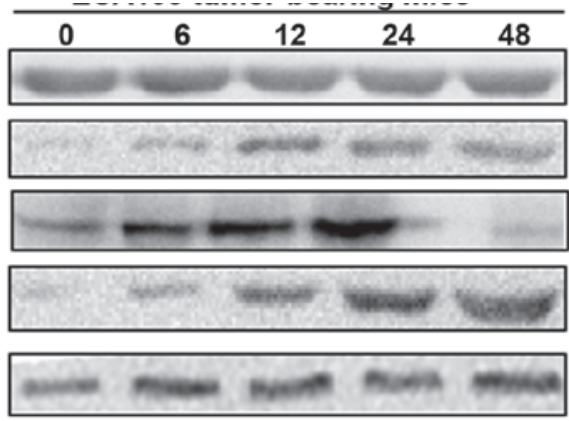

ECA109

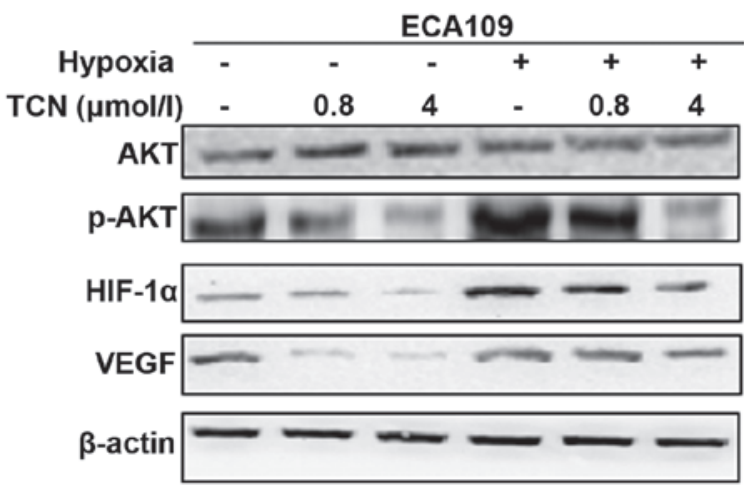

Figure 3. Upregulation of AKT and HIF-1 $\alpha$ by hypoxia can be attenuated by TCN in ESCC cells and xenografts in vivo. (A) Accumulation of HIF-1 $\alpha$, VEGF and p-AKT was observed upon $6 \mathrm{~h}$ of hypoxic incubation, and reached a maximum at $24 \mathrm{~h}$ in ESCC cells and nude mice. (B) For further experiments, the $24 \mathrm{~h}$ time point was selected. The hypoxia-stimulated accumulation of p-AKT, HIF-1 $\alpha$ and VEGF was significantly decreased by TCN. HIF, hypoxia-inducible factor; VEGF, vascular endothelial growth factor; ESCC, esophageal squamous cell carcinoma; TCN, triciribine; p, phosphorylated. 


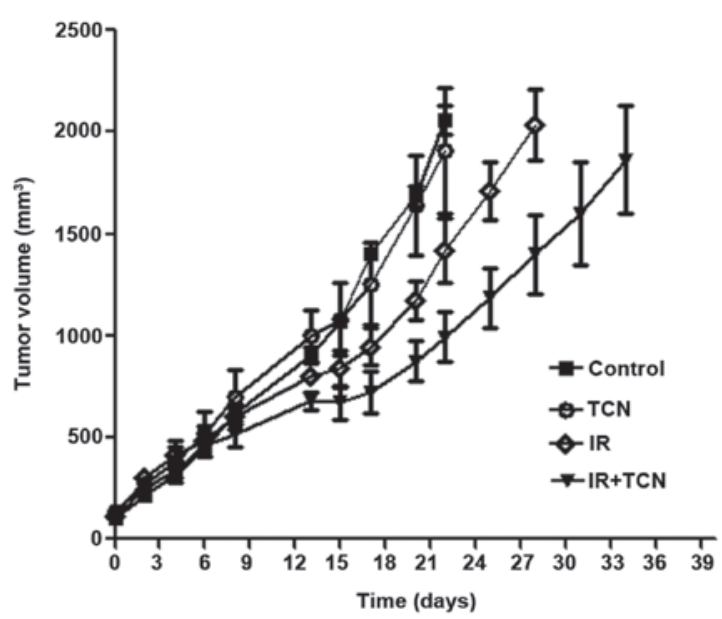

Figure 4. ECA109 tumor volume after $6 \mathrm{~Gy}(4.48 \mathrm{~Gy} / \mathrm{min})$ on day 6 plus or minus $5 \mathrm{mg} / \mathrm{kg}$ TCN on days $0,2,4$ and 6 (mean \pm standard error of the mean, $\mathrm{n}=6$ ). TCN, triciribine; IR, ionizing radiation.

(normoxia, $\mathrm{SER}=1.50$; normoxia + TCN, SER=1.65). Furthermore, this reduction was observed in cisplatin-treated cells, which served as positive controls ( $\mathrm{SER}=1.89$ ) (Table I). These data revealed that TCN could significantly suppress clonogenic proliferation in normoxia and hypoxia, which was particularly evident in hypoxia, and reversed the radio-resistance induced by normoxic or hypoxic conditions in ESCC cells.

The early apoptosis of ESCC cells treated by IR with or without TCN $(4 \mu \mathrm{mol} / \mathrm{l})$ was tested in normoxia and hypoxia. As shown in Fig. 2A, treatment with TCN for $24 \mathrm{~h}$ did not significantly induce apoptosis, and no distinct increase was observed in either normoxia or hypoxia. Notably, the proportion of apoptotic cells was considerably increased in the irradiation-treated group compared with the control group (normoxia, $\mathrm{P}=0.002$; hypoxia, $\mathrm{P}=0.006$ ). In addition, the number of apoptotic cells in the combined treatment group was significantly higher than the number of cells treated with irradiation alone under both normoxic and hypoxic conditions (both $\mathrm{P}=0.003$ ) (Fig. 2B).

It was speculated that the effect of TCN on ESCC cells to IR may be based on the impairment in the repair of DNA double-strand breaks (DSBs). Therefore, the levels of DSBs in ECA109 cells were detected at different times after exposure to IR under either normoxia or hypoxia by immunofluoresence staining of $\gamma$-H2AX foci. As shown in Fig. 2C, the majority of $\gamma-\mathrm{H} 2 \mathrm{AX}$ foci were cleared at $4 \mathrm{~h}$ after exposure to $1 \mathrm{~Gy}$ of X-rays in ECA109 cells without TCN, while $\gamma$-H2AX foci persisted in ECA109 cells that were pretreated with TCN (4 $\mu \mathrm{mol} / 1)$. The average of $\gamma-\mathrm{H} 2 \mathrm{AX}$ foci per cell in cells subjected to combined treatment with TCN and radiation was evident, compared with the radiation-only group, at 0.5 , 4 and $24 \mathrm{~h}$ under normoxia and hypoxia (Fig. 2C) $(\mathrm{P}<0.0001$, $\mathrm{P}=0.0003$ and $\mathrm{P}=0.0008$, respectively). TCN was not as obvious in inducing DNA damage in terms of $\gamma$-H2AX foci induction compared with the controls $(\mathrm{P}=0.5493)$.

Upregulation of AKT and HIF-1 $\alpha$ by hypoxia can be attenuated by TCN in ESCC cells and xenograft in vivo. As aforementioned, the inhibition of AKT phosphorylation was considered to possibly facilitate radiosensitivity in hypoxic environments, and this effect was possibly mediated through the inhibition of the critical transcription factor HIF- $1 \alpha$ and its target gene VEGF. To investigate whether AKT, p-AKT, HIF-1 $\alpha$ and VEGF were involved in combined treatment-induced cell death, western blotting was utilized to examine the protein expression of ESCC ECA109 cells and xenograft of ECA109 in vivo. Accumulation of HIF-1 $\alpha$, VEGF and p-AKT was observed upon the first $6 \mathrm{~h}$ of hypoxic incubation, and reached a maximum at $24 \mathrm{~h}$ (Fig. 3A). Thus, the $24 \mathrm{~h}$ time point was chosen for further experiments. Of note, the hypoxia-stimulated levels of p-AKT, HIF-1 $\alpha$ and VEGF were significantly decreased by TCN (Fig. 3B).

TCN promotes radiation sensitivity in nude mice. To confirm whether TCN exerts a radiosensitization effect on ESCC xenograft in vivo, ECA109 tumor-bearing mice were treated with 6 Gy irradiation and received intraperitoneal injection of TCN $(25 \mathrm{mg} / \mathrm{kg}$ ) every day for 1 week before irradiation.

It was detected that TCN inhibits p-AKT, HIF-1 $\alpha$ and VEGF protein expression in hypoxic ESCC xenografts. By temporarily blocking the tumor blood supply for $5 \mathrm{~min}$ before irradiation, an hypoxic model was established. Following drugs and irradiation administration, either irradiation or combined treatment effectively delayed tumor growth and reduced tumor weight $(\mathrm{P}=0.025$ for irradiation and $\mathrm{P}=0.002$ for $\mathrm{TCN}+\mathrm{IR}$ on the 22th day) (Fig. 4).

In addition, the doubling time of ECA109 tumors was calculated. In the control group and the TCN alone group, the doubling time was $7.3 \pm 0.6$ and $7.9 \pm 0.7$ days, respectively. For the irradiation-treated group, the combination treatment significantly extended the doubling time to $13.8 \pm 0.8$ days $(\mathrm{P}=0.001)$, while in the irradiation alone group, this value was $10.6 \pm 1.3$ days $(\mathrm{P}=0.037)$. In general, these results demonstrated that intraperitoneal injection of TCN enhances the suppression effect of radiation on ESCC in vivo.

\section{Discussion}

To enhance the radiotherapy efficacy against cancer, several strategies have been utilized. Modulation of DNA damage repair, cellular antioxidant machinery, pro-survival signaling, tumor hypoxia state and cell cycle distribution are commonly used targets for the development of radiation sensitizers (20-24).

A central role in the PI3K/AKT pathway is the serine-threonine kinase AKT, since it enables PI3K to phosphorylate membrane-bound phosphatidylinositol diphosphate to generate phosphatidylinositol trisphosphate, and allows p-AKT on Thr308 and Ser473 residues to interact with pyruvate dehydrogenase kinase 1 and mTOR complex 2 (9). Furthermore, p-AKT not only inhibits apoptosis via B-cell lymphoma (Bcl)-2-associated death promoter/Bcl-extra large and glycogen synthase kinase 3 beta/myeloid cell leukemia 1, but also downregulates the transcription factors forkhead box and p53, upregulates nuclear factor- $\kappa \mathrm{B}$ activity, and inhibits pro-caspase 9 (10). In addition, p-AKT mediates a series of pro-survival signals for anti-apoptosis, proliferation, cell growth and angiogenesis (8). In the PI3K/AKT pathway, activated p-AKT mediates diverse pro-survival signals, promotes the malignant phenotype of cancer cells through multiple downstream pathways and correlates with a poor prognosis (7-10). p-AKT also 
increases expression of the HIF-1 $\alpha$ gene and that of its target genes, including VEGF (12). HIF-1 $\alpha$ is an oxygen-sensitive subunit (14), which, under hypoxic conditions, is an important factor for tumor cells to resist IR (15). TCN, which was initially described as a DNA synthesis inhibitor, has recently been shown to function as an inhibitor of AKT (18). Previous studies demonstrated that TCN inhibits AKT phosphorylation at Thr308 and Ser473 and AKT activity in the human prostate cancer cell line PC-3 (18). In addition, TCN sensitized PC-3 cells to tumor necrosis factor-related apoptosis-inducing ligand- and anti-cluster of differentiation 95-induced apoptosis, whereas the cells remained resistant to DNA damaging chemotherapeutics (16). The observed sensitization essentially depended on the phosphorylation status of AKT (16). Despite the lack of studies focused on the radiosensitivity of TCN and p-AKT, we speculated an association between TCN and p-AKT and radiosensitization of ESCC.

In our study, for the first time it was demonstrated that TCN reduced colony formation and induced apoptosis or impairment in the repair of DSBs combined with IR. In addition, TCN downregulated p-AKT, HIF-1 $\alpha$ and VEGF in ESCC cells, and suppressed the growth of ESCC xenografts. These results may complement those from previous studies on TCN, which suggested that TCN may be an antitumor agent in different cancers, and may expand our understanding of the mechanisms of TCN activity (18).

In conclusion, the present results provide evidence that the combined application of TCN and IR may be an effective treatment for ESCC. TCN at low concentrations substantially radiosensitized normoxic and hypoxic ESCC cells by downregulating AKT and HIF-1 $\alpha$, which contributes to tumor aggressiveness, invasiveness and resistance to radiation therapy. Furthermore, our data indicate that this treatment critically depends on a high constitutive AKT phosphorylation level.

\section{References}

1. National Cancer Institute: Cancer Statistics: SEER Stat Fact Sheets: Esophageal Cancer. http://seer.cancer. gov/statfacts/html/esoph.html. Accessed January 1, 2014.

2. Gholipour C, Shalchi RA and Abbasi M: A histopathological study of esophageal cancer on the western side of the Caspian littoral from 1994 to 2003. Dis Esophagus 21: 322-327, 2008

3. Tran GD, Sun XD, Abnet CC, Fan JH, Dawsey SM, Dong ZW, Mark SD, Qiao YL and Taylor PR: Prospective study of risk factors for esophageal and gastric cancers in the Linxian general population trial cohort in China. Int J Cancer 113: 456-463, 2005.

4. Tepper J, Krasna MJ, Niedzwiecki D, Hollis D, Reed CE, Goldberg R, Kiel K, Willett C, Sugarbaker D and Mayer R: Phase III trial of trimodality therapy with cisplatin, fluorouracil, radiotherapy, and surgery compared with surgery alone for esophageal cancer: CALGB 9781. J Clin Oncol 26: 1086-1092, 2008.

5. Liu HC, Hung SK, Huang CJ, Chen CC, Chen MJ, Chang CC, Tai CJ, Tzen CY, Lu LH and Chen YJ: Esophagectomy for locally advanced esophageal cancer, followed by chemoradiotherapy and adjuvant chemotherapy. World J Gastroenterol 11: 5367-5372, 2005.

6. Karar J and Maity A: Modulating the tumor microenvironment to increase radiation responsiveness. Cancer Biol Ther 8: 1994-2001, 2009.
7. Davies MA: Regulation, role, and targeting of Akt in cancer. J Clin Oncol 29: 4715-4717, 2011.

8. Courtney KD, Corcoran RB and Engelman JA: The PI3K pathway as drug target in human cancer. J Clin Oncol 28: 1075-1083, 2010.

9. Hasselblom S, Hansson U, Olsson M, Torén L, Bergström A, Nilsson-Ehle $\mathrm{H}$ and Andersson PO: High immunohistochemical expression of $\mathrm{p}$-AKT predicts inferior survival in patients with diffuse large B-cell lymphoma treated with immunochemotherapy. Br J Haematol 149: 560-568, 2010.

10. Hong JY, Hong ME, Choi MK, Kim YS, Chang W, Maeng CH, Park S, Lee SJ, Do IG, Jo JS, et al: The impact of activated p-AKT expression on clinical outcomes in diffuse large B-cell lymphoma: A clinicopathological study of 262 cases. Ann Oncol 25: 182-188, 2014.

11. Cummins EP and Taylor CT: Hypoxia-responsive transcription factors. Pflugers Arch 450: 363-371, 2005.

12. Jung JE, Lee HG, Cho IH, Chung DH, Yoon SH, Yang YM, Lee JW, Choi S, Park JW, Ye SK and Chung MH: STAT3 is a potential modulator of HIF-1-mediated VEGF expression in human renal carcinoma cells. FASEB J 19: 1296-1298, 2005.

13. Xu Q, Briggs J, Park S, Niu G, Kortylewski M, Zhang S, Gritsko T, Turkson J, Kay H, Semenza GL, et al: Targeting Stat 3 blocks both HIF-1 and VEGF expression induced by multiple oncogenic growth signaling pathways. Oncogene 24: 5552-5560, 2005.

14. Liao D and Johnson RS: Hypoxia: A key regulator of angiogenesis in cancer. Cancer Metastasis Rev 26: 281-290, 2007.

15. Yang X, Zhu HC, Zhang C, Qin Q, Liu J, Xu LP, Zhao LJ, Zhang Q, Cai J, Ma JX, et al: HIF-1 $\alpha ; 1772$ C/T and 1790 G/A polymorphisms are significantly associated with higher cancer risk: An updated meta-analysis from 34 case-control studies. PLoS One 8: e80396, 2013.

16. Yang X, Zhang C, Zhu HC, Qin Q, Zhao LJ, Liu J, Xu LP, Zhang Q, Cai J, Ma JX, et al: HIF-1 $\alpha$ P582S and A588T polymorphisms and digestive system cancer risk-a meta-analysis. Tumour Biol 35: 2825-2830, 2014.

17. Guo Q, Dai SB, Shen F, Yu D, Shen ST, Zhang Q, Huang JX and Wu ZD: VEGF+405G/C (rs2010963) polymorphisms and digestive system cancer risk: A meta-analysis. Tumour Biol 35: 4977-4982, 2014

18. Gürsel DB, Connell-Albert YS, Tuskan RG, Anastassiadis T, Walrath JC, Hawes JJ, Amlin-Van Schaick JC and Reilly KM: Control of proliferation in astrocytoma cells by the receptor tyrosine kinase/PI3K/AKT signaling axis and the use of PI-103 and TCN as potential anti-astrocytoma therapies. Neuro Oncol 13: 610-621, 2011.

19. Dieterle A, Orth R, Daubrawa M, Grotemeier A, Alers S, Ullrich S, Lammers R, Wesselborg S and Stork B: The Akt inhibitor triciribine sensitizes prostate carcinoma cells to TRAIL-induced apoptosis. Int J Cancer 125: 932-941, 2009.

20. Kesari S, Advani SJ, Lawson JD, Kahle KT, Ng K, Carter B and Chen CC: DNA damage response and repair: Insights into strategies for radiation sensitization of gliomas. Future Oncol 7: 1335-1346, 2011.

21. Pajonk F, Vlashi E and McBride WH: Radiation resistance of cancer stem cells: The 4 R's of radiobiology revisited. Stem Cells 28: 639-648, 2010

22. Ahmed KM and Li JJ: NF- $\mathrm{KB}$-mediated adaptive resistance to ionizing radiation. Free Radic Biol Med 44: 1-13, 2008.

23. Zhang C, Yang X, Zhang Q, Guo Q, He J, Qin Q, Zhu H, Liu J, Zhan L, Lu J, et al: STAT3 inhibitor NSC74859 radiosensitizes esophageal cancer via the downregulation of HIF-1 $\alpha$. Tumour Biol 35: 9793-9799, 2014.

24. Zhang Q, Zhang C, He J, Guo Q, Hu D, Yang X, Wang J, Kang Y, She R, Wang Z, et al: STAT3 inhibitor stattic enhances radiosensitivity in esophageal squamous cell carcinoma. Tumour Biol 36: 2135-2142, 2015. 